\title{
3D Numerical Simulation of Gas Flow and Selective Catalytic Reduction (SCR) of NO in the Honeycomb Reactor
}

\author{
Jongchol Om \\ Department of mechanics \\ University of science \\ Poyngyang, DPR of Korea \\ M15669046883@163.com
}

\author{
Weihong Wu \\ State Key Laboratory of Clean Energy Utilization \\ Zhejiang niversity \\ Hangzhou, PR China \\ whwu2000@vip.163.com
}

\author{
Peidong Ji \\ State Key Laboratory of Clean Energy Utilization \\ Zhejiang niversity \\ Hangzhou, PR China \\ jipd@zju.edu.cn
}

\begin{abstract}
Selective catalytic reaction(SCR) of NOx by ammonia is a very efficient method to reduce the NOx emission from coal-fired power plants and large boilers. The ammonia is injected into the exhaust gas stream and is mixed NOx. The mixture passes through the honeycomb-type catalyst bed, where NOx reacts on the catalyst surface with adsorbed ammonia in the presence of excess oxygen, decomposing into diatomic nitrogen and water molecules, thereby reducing the NOx level in the exhaust gas. The present study discusses theNOx reduction mechanism in the honeycomb channel.In this work,3-dimensional computational fluid dynamics (CFD) simulations are carried out to investigate the effects of the various state parameters on the De-NOx reaction at the catalyst. Research results showed that the gas temperature, flow velocity and $\mathrm{NH}_{3} / \mathrm{NO}$ concentration ratio all are important parameters of theNOx reduction with ammonia in the honeycomb catalyst.
\end{abstract}

Keywords-Selective catalytic reaction(SCR); simulations; CFD; honeycomb;De-NOx reaction

\section{INTRODUCTION}

Nitrogen oxides(NOx, including NO,NO2 and N2O) emissions from power and chemical plants are major environmental concerns that include increasing ground level ozone, formation of acid rain , forest damage, and formation of fine particles in the atmosphere. Therefore, the technologies to reduce NOx emission are of great importance. Being one of such technologies, selective catalytic reduction(SCR) of $\mathrm{NOx}$, is a very promising method, due to its high efficiency, selectivity and low expense[1-2].

Because of degradation during long-time operation , catalysts must be periodically exchanged or regenerated, hence it is needed to optimize the operation conditions of De-NOx equipment and predict the lifetime of the catalyst.

SCR performance can be improved by operating the catalysts at different temperatures to optimize their maximum activity and gas residence time also influences catalytic activity, as well as inlet ammonia concentration.

Ammonia slip is one of the common problems with SCR system, it can occur when catalyst temperatures are not in the optimal range for the reaction, or when too much ammonia is injected into the process[3-4].

The present study investigates the effects of various parameters (temperature, inlet $\mathrm{NH}_{3} / \mathrm{NO}$ concentration ratio, gas space velocity) on the performance of honeycomb structured catalysts using three-dimensional CFD modeling and simulation.

\section{MATHEMATICAL MODEL}

In present study, we ignore the heat transfer in the reactor because the concentrations of reactants are extremely low and the energy accumulation is insignificant. Furthermore, we assume a uniform catalyst distribution, an equally inlet flow over the entire cross section of the honeycomb, and an ideal homogeneous premixing of the exhaust gas and reactants. Based onthese assumptions, the simulation of the physicochemical processes occurring in the whole system is reduced to the analysis of a single channel. In this model, we also assume that the diffusion in the gas phase and in the catalyst material of the reactant species obeys FICK's law and the gas flow in the honeycomb channel is turbulent[5].

\section{A. Reaction Kinetics}

The reaction mechanism for the reduction of NO using $\mathrm{NH}_{3}$ over catalyst is described as following;

$$
\begin{array}{r}
4 \mathrm{NO}+4 \mathrm{NH}_{2}+\mathrm{O}_{2} \rightarrow 4 \mathrm{~N}_{2}+6 \mathrm{H}_{2}(1) \\
4 \mathrm{NH}_{2}+3 \mathrm{O}_{2} \rightarrow 2 \mathrm{~N}_{2}+6 \mathrm{H}_{2} \mathrm{O}(2)
\end{array}
$$

The following rate equation taken from the literature on intrinsic SCR kinetics is used in this study. 


$$
\begin{array}{r}
\mathrm{r}_{1}=\mathrm{k}_{1} \mathrm{C}_{\mathrm{NO}} \frac{\mathrm{a \textrm {NW } _ { 3 }}}{1+\mathrm{ar}_{\mathrm{NH}}}(3) \\
\mathrm{r}_{2}=\mathrm{k}_{2} \mathrm{C}_{\mathrm{NH}}(4) \\
\mathrm{k}_{\mathrm{i}}=\mathrm{A}_{\mathrm{i}} \exp \left(-\frac{\mathrm{E}_{\mathrm{i}}}{\mathrm{RT}}\right), \mathrm{i}=1,2(5) \\
\mathrm{a}=\mathrm{A}_{0} \exp \left(-\frac{\mathrm{E}_{\mathrm{a}}}{\mathrm{RT}}\right)(6)
\end{array}
$$

Where $\mathbb{E}_{\mathrm{l}}$ is the activated energy $(\mathrm{J} / \mathrm{mol}), \mathrm{R}$ is the gas constant $(\mathrm{J} / \mathrm{mol} \mathrm{k})$ and $\mathrm{T}$ is the temperature $(\mathrm{k})[6]$.

\section{B. Transport Phenomena}

The governing equations for the exhaust gas flow are continuity equation, momentum equation ( $\mathrm{N}-\mathrm{S}$ equation), and mass conservation equation of species I, which are written as

$$
\begin{array}{r}
\frac{\partial p}{\partial t}+\nabla \cdot(\rho \vec{u})=0(7) \\
\rho \frac{\partial \vec{u}}{\partial t}+\rho(\vec{u} \nabla) \vec{u}=-g u d(p)+\left(\mu+\mu_{t}\right) d \vec{u}(8) \\
\frac{\partial C_{i}}{\partial t}+\nabla \cdot\left(-D_{i} \nabla c_{i}+\vec{u} c_{1}\right)=\mathbb{R}_{i} \\
i=N O \text { or }, N_{g} \mathbb{R}_{1}=r_{1}, \quad \mathbb{R}_{2}=r_{1}+r_{2} \cdot(9)
\end{array}
$$

where $D_{j}$ and $C_{i}$ denote the diffusion coefficient $\left(\mathrm{m}^{2} / \mathrm{s}\right)$ and the specie core, respectively.

We assumed that reaction rate $\mathbb{R}_{i}$ is negligible in the gas phase and it isconsiderable only in the catalyst material, because the reaction rate between $\mathrm{NO}$ and $\mathrm{NH}_{3}$ without the catalyst is very slow.

The exhaust gas flow is usually turbulent. In this study, the turbulent flow is described as $\mathrm{RNG} \times-\mathrm{z}$ model.

$$
\begin{aligned}
& \frac{a}{\partial t}(\mathrm{\rho k})+\nabla(\mathrm{puk})=\nabla \cdot\left[\left(\mu+\frac{\mu_{t}}{\nabla_{k}}\right) \nabla k\right]+R_{k}-\rho g(10) \\
& \frac{\partial}{\partial t}(p z)+\nabla(p u s)=\nabla \cdot\left[\left(\mu+\frac{\mu_{t}}{\sigma_{\varepsilon}}\right) \nabla z\right]+ \\
& C_{1} \frac{\varepsilon}{k} P_{k}-C_{2} p \frac{\varepsilon^{2}}{k}(11) \\
& \mu_{\mathrm{t}}=\mathrm{pC}_{\mathrm{u}} \frac{\mathrm{k}^{2}}{\mathrm{q}}
\end{aligned}
$$

The constants appearing in Eqs, (10)-(12) are $\mathrm{C}_{\mu_{s}}=0.09$, $\sigma_{\mathrm{k}}=1.0, \sigma_{\mathrm{z}}=1.30, \mathrm{C}_{1}=1.44$, and $\mathrm{C}_{2}=1.92$.[7]

\section{CFD SIMULATIONS AND PARAMETER

\begin{tabular}{|c|c|c|c|}
\hline $\begin{array}{c}\text { Kinetic } \\
\text { parameter }\end{array}$ & $\begin{array}{c}\text { Physical } \\
\text { meaning }\end{array}$ & value & unit \\
\hline $\begin{array}{l}\mathbb{E}_{2} \\
\mathbb{E}_{2} \\
k_{2} \\
k_{2} \\
A_{0} \\
E_{0} \\
s_{5} \\
V_{g}\end{array}$ & $\begin{array}{l}\text { Activate energy } \\
\text { Activate energy } \\
\text { Rate constant } \\
\text { Rate constant } \\
\text { reaction } \\
\text { constant } \\
\text { Activate energy } \\
\text { BET surface } \\
\text { Totalpore } \\
\text { volume }\end{array}$ & $\begin{array}{c}41900 \\
85400 \\
1.19 \times 10^{-9} \\
6.73 \times 10^{7} \\
2.57 \\
\times 10^{-17} \\
-2.37 \times 10^{8} \\
73.75 \\
0.1658\end{array}$ & $\begin{array}{c}\mathrm{j} / \mathrm{mol} \\
\mathrm{j} / \mathrm{mol} \\
\mathrm{s}^{-1} \\
\mathrm{~s}^{-1} \\
\mathrm{~m}^{2} / \mathrm{mol} \\
\mathrm{j} / \mathrm{mol} \\
\mathrm{m}^{2} / \mathrm{s} \\
\mathrm{cm}^{2} / \mathrm{g}\end{array}$ \\
\hline
\end{tabular} VALUES}

Three-dimensional simulation are carried out with the commercial CFD simulation package Ansys 14.5 Fluent.

Fig. 1 shows a schematic diagram of the honeycomb element SCR reactor and the computational domain.

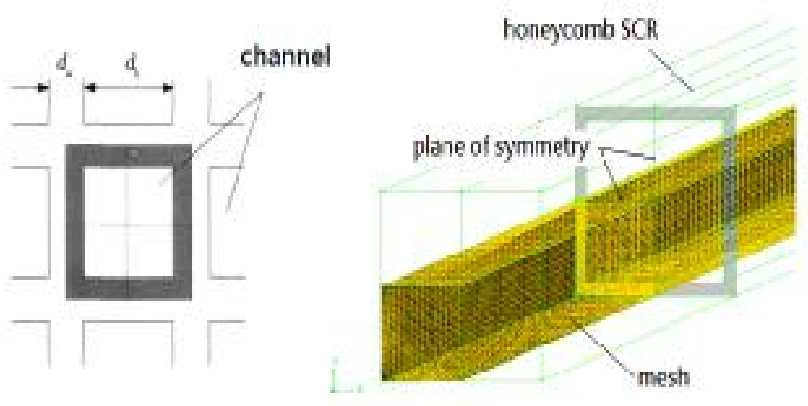

Figure 1.Honeycomb SCR channel and computational mesh.

The simulation parameters such as the inflow properties and the physical properties of the SCR reactor are listed in table 1 and 2 .

Table 1. Physical property of the SCR [8-9]

The discretization of the governing equations and the boundary conditions was established on the basis of the geometrical symmetry. The elements of mesh all are hexahedron and the mesh number is $80 \times 80 \times 600$, about 3.80million.

For considering the interface between the catalyst and the gas phase, we can be written as follow:

$$
\mathrm{D}_{\mathrm{e}} \frac{\partial u_{i}}{\partial n}=\mathrm{D}_{\mathrm{g}} \frac{\partial u_{\mathrm{i}}}{\partial \mathrm{z}}(13)
$$

Where n: normal vector, $\mathrm{D}_{\varepsilon}$ : diffusion coefficient in the catalyst, $\mathrm{D}_{\mathrm{g}}$ : diffusion coefficient in gas phase.

TABLE 2. Numerical Simulation condition

\begin{tabular}{|c|c|}
\hline Parameters & value \\
\hline Length of SCR layer & $600 \mathrm{~mm}$ \\
Cell size & $6 \times \mathbf{6 m m}$ \\
Thickness & $1 \mathrm{~mm}$ \\
Gas velocity & $0.1-10 \mathrm{~m} / \mathrm{s}$ \\
temperature & $300-400 \cdot \mathrm{C}$ \\
NO & $1000 \mathrm{ppm}$ \\
NH $_{\mathbf{z}}$ & $900-1100 \mathrm{ppm}$ \\
Tortuosity & 4 \\
Porosity & 0.4 \\
\hline
\end{tabular}

Since the diffusion coefficient and the gas viscosity are dependent of temperature, in this study the following corrections are used in this work[10-11].

$$
\begin{array}{r}
\mathrm{D}_{\mathrm{e}}=\frac{\varepsilon}{\tau} \times 9.70 \times 10^{2} \times \overline{\mathrm{r}} \times \sqrt{\frac{\mathrm{T}}{\mathrm{M}_{\mathrm{i}}}}(14) \\
\mathrm{D}_{\mathrm{g}}=2.695 \times 10^{-2} \frac{\sqrt{\mathrm{T}^{3}\left(0 \mathrm{M}_{\mathrm{i}}+\mathrm{M}_{\mathrm{Q}} /\left(2 \times 10^{3} \mathrm{M}_{\mathrm{i}} \mathrm{M}_{\mathrm{a}}\right)\right.}}{\mathrm{p \sigma _{ \textrm {i } } \square _ { \mathrm { Q } } \Omega _ { \mathrm { D } }}}(15)
\end{array}
$$




$$
\ln \mu=A_{0}+B_{0} \ln T+\frac{B_{1}}{T}+\frac{B_{2}}{T^{2}}(16)
$$

$A_{0}=1.209188, \mathbb{B}_{0}=0.6916243, \mathbb{B}_{1} \times 10^{-3}=0.0576372$,

$$
\mathrm{B}_{2} \times 10^{-5}=-0.1429573 \text {. }
$$

Where $\varepsilon$ and $\tau$ are the tortuosity and the porosity, $\mathrm{M}_{\mathrm{j}}$ and $\mathrm{M}_{\mathrm{o}}$ present the molar mass $(\mathrm{kg} / \mathrm{mol})$ of gas species, respectively. And $\sigma_{i}$ and $\sigma_{\sigma}$ are the diameters $(\mathrm{m})$ of the gas species. Besides, $\mathrm{P}$ is the pressure $(\mathrm{Pa})$ and $\Omega_{\mathrm{D}}$ is collision integrals $[8]$.

\section{RESULT AND DISCUSSION}

Fig .2shows the flow velocity profile in a honeycomb channel. The development of the velocity distribution can be portrayed by a sequence of velocity profiles along the channel.
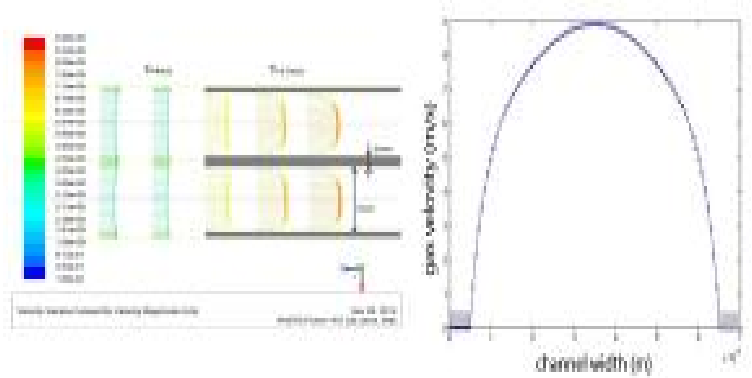

Figure2.gas velocity profile in the honeycomb chanel.

It is clearly seen that the gas inflow at the inlet cross section has homogeneous velocity $4 \mathrm{~m} / \mathrm{s}$, but the maximum speed of the developed flow in a channel is $8.9 \mathrm{~m} / \mathrm{s} . \mathrm{It}$ is clear that the gas flow non-uniformly enters the channel and it is gradually developed up to the point, $60 \mathrm{~mm}$ from the inlet, since the velocity profile has two peaks at upstream and it has one peak at downstream in this figure.

Fig .3 shows the decrease of the NO concentration profiles at various axial positions along the channels with two catalyst layerswhen the inlet gas temperature is $380^{\circ} \mathrm{C}$, the flow velocity is $4 \mathrm{~m} / \mathrm{s}$, and inlet $\mathrm{NO}$ and $\mathrm{NH}_{3}$ concentration both are 1000ppm respectively.

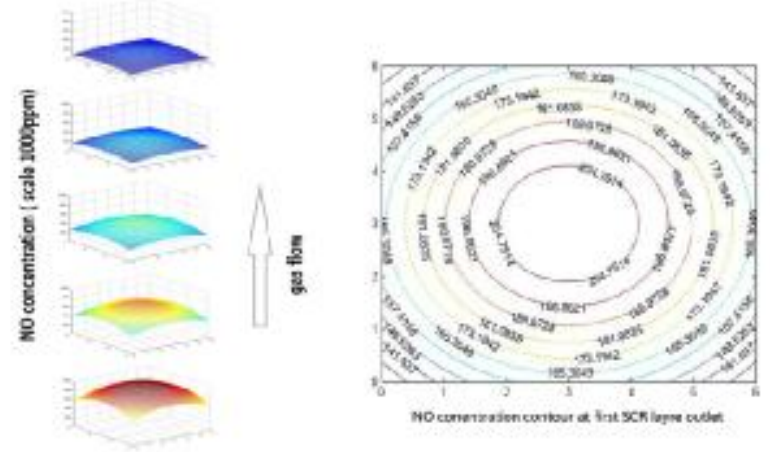

Figure 3.Developing NO concentration profile in a channel and No concentration contour at the outlet section.

After the exhaust gas passes through the first catalyst layer, then continually passes through the second one. The results show that the NO conversion of the first layer and the second layer is $82.7 \%$ and $97 \%$, respectively.
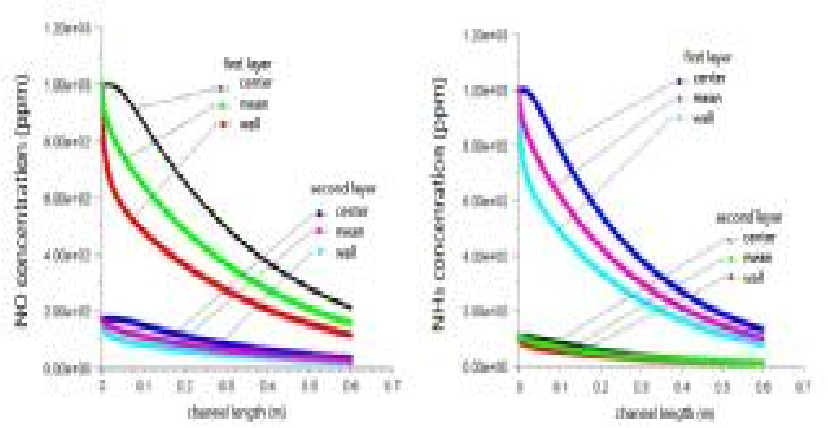

Figure 4.concentrations of $\mathrm{NO}$ and $\mathbf{M H}_{2}$ along the length of the channel

Furthermore, the NO reduction reaction is suppressed in the corner region due to the flow stagnation.

Fig .4 shows the concentration of $\mathrm{NO}$ and $\mathrm{NH}_{3}$ along the channel length for two catalyst layers.

Here, three curve lines represent the concentration profile in the center of channel, the profile of mean concentration at cross section and the profile of concentration at the catalyst wall surface, respectively. The concentration at the catalyst wall surface is significantly lower than other two concentrations.

Fig .5 shows the NO concentration distribution at $60 \mathrm{~mm}$ across section from the channel inlet.

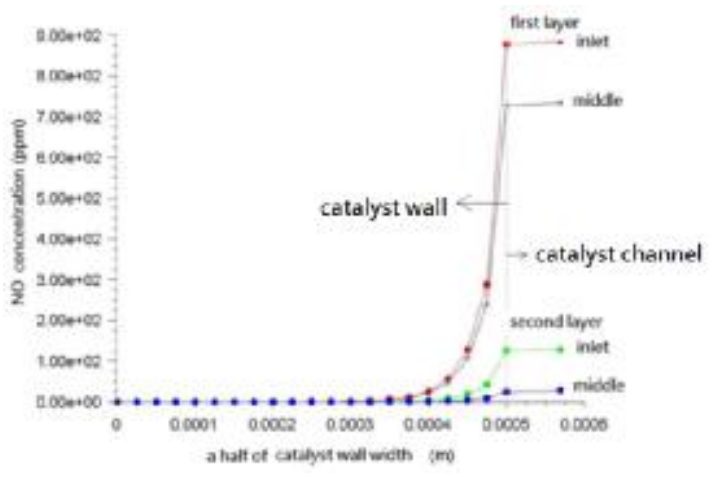

Figure 5. NO concentration profiles in the catalyst material(two SCR layers).

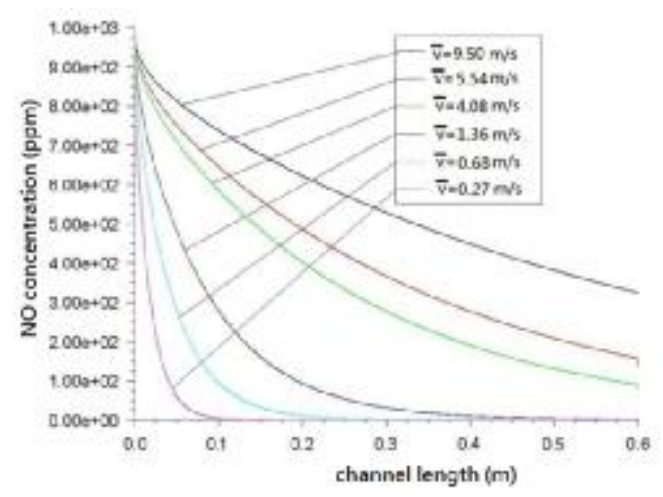

Figure 6.Effect of gas velocity on NO concentration.

It is clear that the NO reduction reaction only was occurred in the thin region of the catalyst wall. When the gas temperature is $380^{\circ} \mathrm{C}$,the diffusion thickness of the reactants is about $0.25 \mathrm{~mm}$ in the catalyst material, this value is $50 \%$ of whole catalyst volume and the others all 
are the dead zones.

Fig .6 shows the NO concentration reductes along the length of the channel for different values of the inlet velocity. This simulation indicates that the increase in inlet flow velocity results in the decrease of the $\mathrm{NO}$ conversion because of less residence time.

The NO reduction rates under different operating temperature are illustrated in fig .7. From this figure, it can be observed that the increase of operating temperature results in the increase of the NO conversion efficiency.

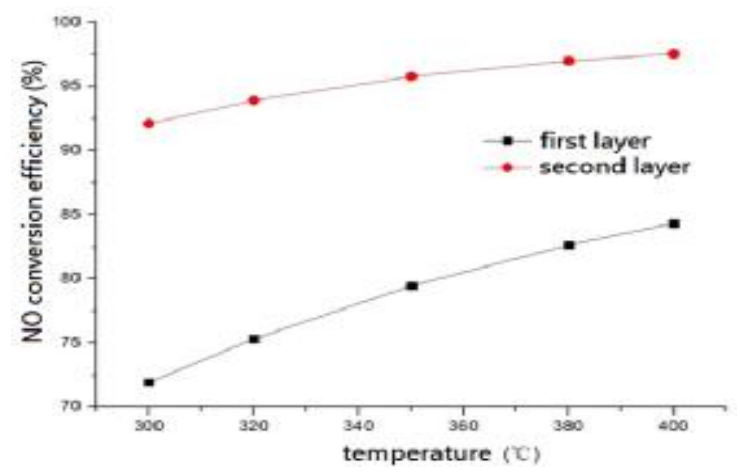

Figure 7.Effect of temperature on NO conversion efficiency.
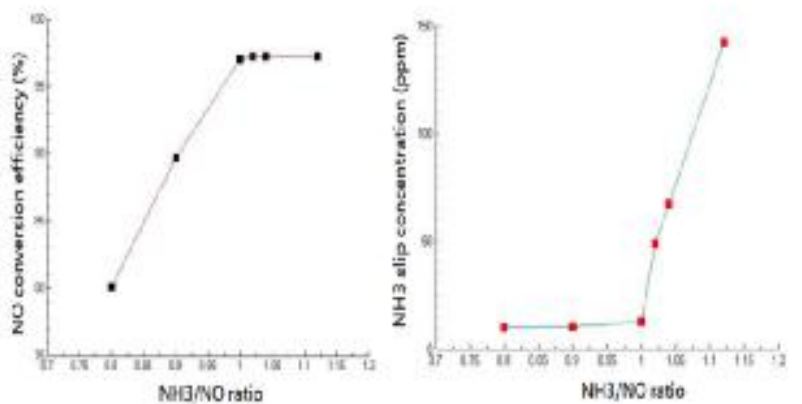

Figure 8.Effect of $\mathrm{NH}_{2} / \mathrm{NO}$ ratio on $\mathrm{NO}$ conversion and $\mathrm{NH}_{2}$ slip.

Fig .8 shows the effect of $\mathrm{NH}_{3} / \mathrm{NO}$ ratio onthe $\mathrm{NO}$ conversion efficiency and the ammonia slip, when the inlet gas temperature is $380^{\circ} \mathrm{C}$, the flow velocity is $5.5 \mathrm{~m} / \mathrm{s}$, and inlet $\mathrm{NO}$ and $\mathrm{NH}_{3}$ concentration both are $1000 \mathrm{ppm}$ respectively.

The results show that the NO conversion efficiency increases as $\mathrm{NH}_{3} / \mathrm{NO}$ ratio is increased upto the maximum value near stoichiometric condition, and simultaneously the ammonia slipis also increased with increasing of $\mathrm{NH}_{\mathrm{z}} / \mathrm{NO}$ ratio.

From the simulation, when $\mathrm{NH}_{3} / \mathrm{NO}$ ratio is $1.1, \mathrm{NH}_{3}$ slip is $10 \mathrm{ppm}$, less than the accepted value and $\mathrm{NO}$ conversion efficiency can be reached $97.2 \%$.

\section{CONCLUSIONS}

In the present study, 3D numerical simulation was applied to investigate the effects of the various operating parameters on the selective catalytic De-NOx reaction in a honeycomb channel.

The gas flow is entirely developed up to point, $60 \mathrm{~mm}$ from the channel inlet.

From three dimension $\mathrm{NO}$ and $\mathrm{NH}_{\mathbf{3}}$ concentration profiles along the duct channel, it is clearly verified that the NO reduction reaction is suppressed in the corner region due to the flow stagnation. This is very important for designing honeycomb SCR system.

The results show that as the gas flow velocitiesincrease,theconversion efficiencies decrease and the ammonia slip increase. This is due to the decrease of interaction time between $\mathrm{NO}, \mathrm{NH}_{3}$ and the catalyst.

The result shows that the SCR reaction only occurs in thin region close to the catalyst wall surface (about $0.25 \mathrm{~mm}$ ) and the rest is dead zone. Therefore, it gives the possibility of saving the catalyst resources to us.

The result shows that the NO conversion efficiency increase when the temperature of the inlet gas and $\mathrm{NH}_{3} / \mathrm{NO}$ ratio both are increased.

The larger the $\mathrm{NH}_{\frac{3}{3}} / \mathrm{NO}$ ratio, the more significant the $\mathrm{NH}_{3}$ slip phenomenon because of the ammonia excess, otherwise this can be avoided by using a higher operating temperature.

The results of this paper can be contributed to the improvement of SCR system in order to meet the increasingly stringent NOx emissions regulations.

\section{ACKNOWLEDGEMENT}

This work was supported by the State Key Laboratory of Clean Energy Utilization, Zhejiang University, China. This paper was completed when the first author was a visiting at the Energy Engineering of Zhejiang University.

\section{REFERENCES}

[1] Oghare V Ogidiama, Tariq Shamim,"Performance analysis of industrial selective catalytic reduction (SCR) systems,"Energy Procediavol.61 ( 2014 ),pp.2154-2157

[2] S.R. Dhanushkodi, N. Mahinpeya,b, M. Wilson,"Kinetic and 2D reactor modeling for simulation of the catalytic reduction of NOxin the monolith honeycomb reactor, " process safety and environment protection vol.86 (2008),pp. 303-309

[3] B. Roduit and A. Baiker."3-D modeling of SCR of NOx by on vanadia honeycomb catalysts AIChE Journal Vol. 44, No. 12

[4] Hong Mei F, Zhao Ping Z, Bao Sheng J, et al. "Numerical calculation of a honeycomb shaped catalyst denitration process, "Journal of engineering for thermal energy and power, vol.22,no.4

[5] KenjiTanno, Ryoichi Kurose, TakenobuMichioka. "Direct numerical simulation of flow and surface reaction in de-NOx catalyst, " Advanced Powder Technology vol.24 (2013),pp. 879-885

[6] JianXun D, SongLling W, YongHhua L."Mathematical simulation study of a selective catalytic reduction based flue gas denitration process, "Journal of engineering for thermal energy and power, vol.22,no. 5

[7] TuncerCebec."Analysis of Turbulent Flows with Computer Programs, " Oxford, UK:. 3rd ed., 2013,

[8] JiangYo, Xiang Gao."Study on titania-based SCR catalysts and their poisoning mechanism of potassium and lead, "Ph.D. dissertation. China: Zhejiang university ;2010

[9] G. Schaub, D. Unruh, J. Wang, T. "Kinetic analysis of selective catalytic NOx reduction (SCR) in a catalytic filter, " Chemical Engineering and Processing 42 (2003) ,pp.365-371

[10] Chyi-Tsong Chen, Wei-Lun Tan."Mathematical modeling, optimal design and control of an SCR reactor for NOx removal, "Journal of the Taiwan Institute of Chemical Engineers 43 (2012),pp. 409-419

[11] Juan Yang, Hongtao Ma, et al. "SCR catalyst coated on low-cost monolith support for flue gas denitration of industrial furnaces, " Chemical Engineering Journal vol.230 (2013),pp. 513-52 